\title{
ПРОБЛЕМА ВЛИЯНИЯ СИНМЕТАМОРФИЧЕСКИХ ДЕФОРМАЦИЙ НА МИНЕРАЛЬНУЮ И ХИМИЧЕСКУЮ ДИФФЕРЕНЦИАЦИЮ В ТЕЛАХ МЕТАБАЗИТОВ НА ПРИМЕРЕ БУДИНЫ МЕТАГАББРО-НОРИТА ИЗ РАЙОНА СЕЛА ГРИДИНО, БЕЛОМОРСКИЙ ПОДВИЖНЫЙ ПОЯС
}

\section{Травин В.В.}

Институт геологии КарНЦ РАН, ПетрГУ, Петрозаводск, vetr@list.ru

Как известно из литературы, деформация и химическая сегрегация почти всегда сопровождают метаморфизм [6 и др.]. Несмотря на «универсальность» этого утверждения, для высокотемпературных метаморфических преобразований сегрегации обсуждаются в основном на примерах мигматитов [6]. Пример из района села Гридино, первые данные изучения которого рассматриваются в настоящем сообщении, показывает возможности «дальней» миграции элементов в базитах, испытывающих метаморфические преобразования в условиях высоких температур и давлений.

Уплощенное тело метабазитов мощностью не более семи метров (рис.) вытянуто по простиранию вмещающей его субмеридиональной крутопадающей пластической зоны сдвига. Тело вскрыто обнажением на протяжении 20 м. Химический состав пород (таблица 1) указывает на принадлежность их реперному для БПП комплексу лерцолитов-габбро-норитов [3] с возрастом около 2.4 млрд. лет [5]. Очевидно, это тело представляет собой одну из многочисленных в районе даек габбро-норитов, подвергнутую интенсивным деформациям, или будину такой дайки.
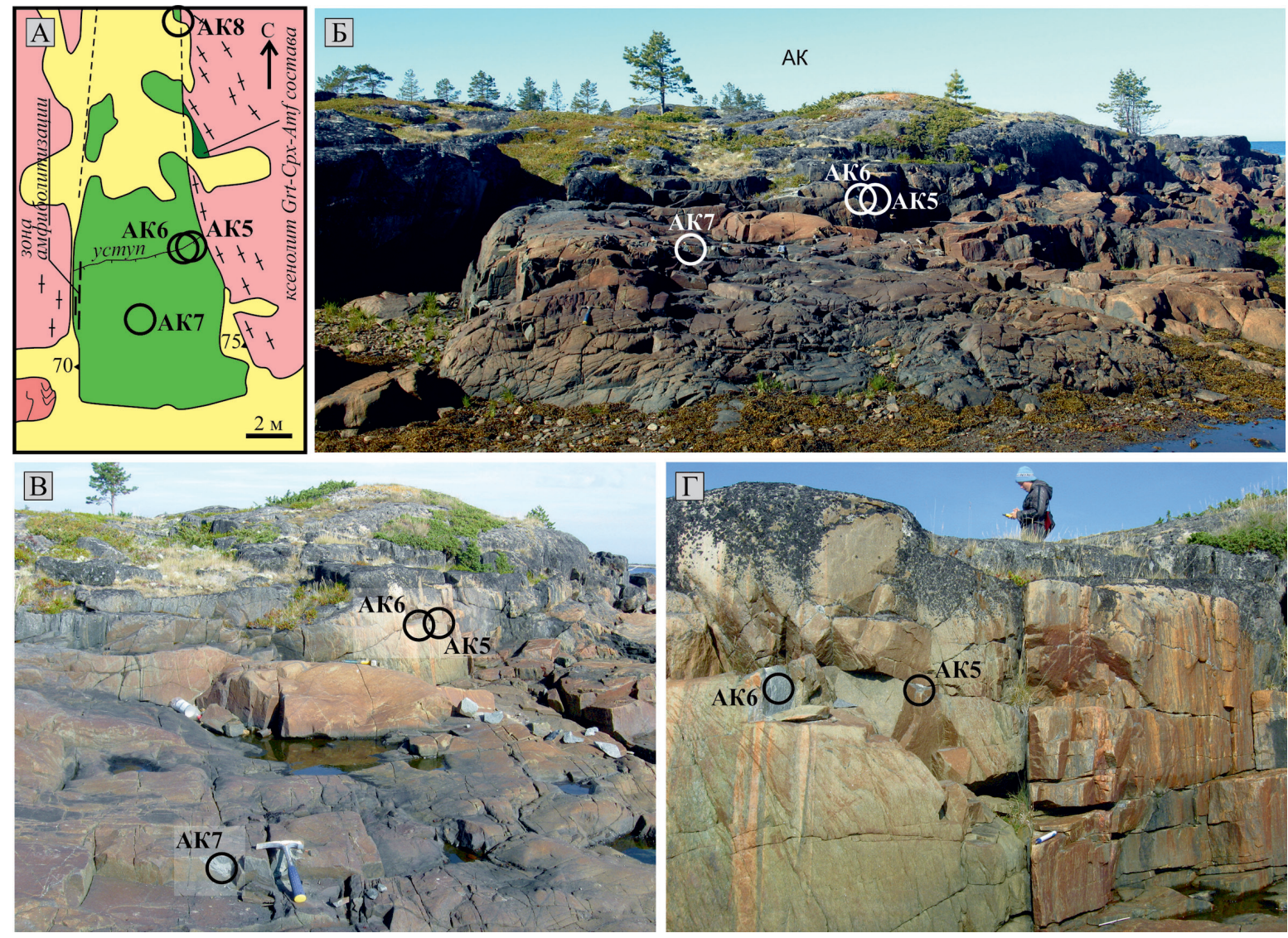

Рис. Тело метагаббро-норитов.

А - план обнажения, по зарисовке в полевом дневнике (с упрощениями). Б-Г - фотографии, сделанные с юга: Б - общий вид береговой части обнажения, В, Г - центральная и восточная части тела. В - в центральной (слева) части обнажения породы имеют серый цвет, в зоне восточного контакта с гнейсами (справа) - зеленый. Г - породы с сегрегационными агрегатами гранатита, удлиненные параллельно минеральной линейности пород; маркер указывапет на контакт тела метагаббро-норитов и вмещающих гнейсов. Кружками отмечены места взятия образцов, упоминаемых в тексте. 
Таблица 1. Химические составы образцов метагаббро-норитов, места отбора которых показаны на рисунке.

\begin{tabular}{|l|l|l|l|l|}
\hline \multirow{2}{*}{} & \multicolumn{4}{|c|}{ Метагаббро-нориты } \\
\cline { 2 - 5 } & \multicolumn{1}{|c|}{ АК5 } & \multicolumn{1}{|c|}{ АК6 } & \multicolumn{1}{|c|}{ АК8 } & \multicolumn{1}{c|}{ АК7 } \\
\hline $\mathrm{SiO}_{2}$ & 49.68 & 49.30 & 49.04 & 48.04 \\
\hline $\mathrm{Fe}_{2} \mathrm{O}_{3}$ & 0.42 & 0.73 & 0.60 & 0.46 \\
\hline $\mathrm{Al}_{2} \mathrm{O}_{3}$ & 9.18 & 12.63 & 10.88 & 7.84 \\
\hline $\mathrm{FeO}$ & 8.47 & 9.34 & 9.91 & 8.11 \\
\hline $\mathrm{MnO}$ & 0.167 & 0.181 & 0.199 & 0.198 \\
\hline $\mathrm{MgO}$ & 16.02 & 13.35 & 15.67 & 21.14 \\
\hline $\mathrm{CaO}$ & 1010 & 820 & 842 & 710 \\
\hline $\mathrm{Na}_{2} \mathrm{O}$ & 1.65 & 1.86 & 1.81 & 0.91 \\
\hline $\mathrm{K}_{2} \mathrm{O}$ & 047 & 043 & 041 & 026 \\
\hline $\mathrm{H}_{2} \mathrm{O}$ & 0.08 & 0.16 & 0.11 & 0.05 \\
\hline$\Pi_{\Pi}$ & 1.28 & 1.13 & 1.01 & 1.02 \\
\hline $\mathrm{P}_{2} \mathrm{O}_{5}$ & 0.10 & 0.15 & 0.14 & 0.11 \\
\hline $\mathrm{Cr}_{2} \mathrm{O}_{3}$ & 0.294 & 0.222 & 0.257 & 0.480 \\
\hline $\mathrm{V}_{2} \mathrm{O}_{5}$ & 0.051 & 0.036 & 0.045 & 0.046 \\
\hline $\mathrm{CoO}$ & 0.008 & 0.001 & 0.008 & 0.010 \\
\hline $\mathrm{NiO}$ & 0.060 & 0.055 & 0.064 & 0.098 \\
\hline $\mathrm{CuO}$ & 0.009 & 0.026 & 0.011 & 0.005 \\
\hline $\mathrm{ZnO}$ & 0.012 & 0.010 & 0.013 & 0.011 \\
\hline $\mathrm{CyMмa}$ & 99.89 & 99.73 & 99.87 & 99.99 \\
\hline
\end{tabular}

Породы представлены парагенезисами: CpxJd3-3+GrtPrp40+Prg+Opx+PlAn30+Qtz (AK5), CpxJd7-26+GrtPrp39-42+Prg+PlAn30 (AK6), CpxJd20-25+GrtPrp42+Prg+Opx+PlAn20 (AK8), CpxJd2-3+GrtPrp46+Prg+Opx (АК7). Анализы выполнены в лаборатории анализа вещества ИГ КарНЦ РАН.
Метагаббро-нориты имеют полосчатость, сланцеватость и минеральную линейность, ориентированные параллельно контактам тела и текстурам вмещающих гнейсов, вовлеченных в пластическую зону сдвига. Полосчатость пород обусловлена неравномерностью распределения в них породообразующих метаморфических минералов, линейность и сланцеватость - субпараллельной ориентировкой их зерен. Сегрегационные обособления разного состава сильно вытянуты параллельно минеральной линейности пород, наиболее эффектно они представлены в восточном эндоконтакте тела (рисунок, Г). Во внутренней части тела породы с четкой линейностью перемежаются с разновидностями, в которых линейность выражена слабее. Последние отличаются также более темным, темно-серым, цветом (рисунок, В).

Вконтактовойсгнейсамизонегаббро-нориты испытали полную перекристаллизацию с образованием парагенезиса $\mathrm{Cpx}+\mathrm{Grt}+\mathrm{Amf}+\mathrm{Pl}+\mathrm{Qtz} \pm \mathrm{Opx}$ (Сpх - омфацит с содержанием жадеитовой молекулы до 26\%, Amf - паргасит и эденит), что обычно для габбро-норитов района, испытавших синдеформационную эклогитизацию в раннесвекофеннских пластических зонах сдвига $[8,4]$. Составы минералов приведены в таблице 2 .

Упомянутые выше серые породы со слабо выраженной линейностью характеризуются бесплагиоклазовым составом. В изученном образце АК7 они представлены парагенезисом $\mathrm{Cpx}+\mathrm{Grt}+\mathrm{Prg}+\mathrm{Opx}$ и содержат немногочисленные

Таблица 2. Составы минералов образцов АК5 и АК7.

\begin{tabular}{|c|c|c|c|c|c|c|c|c|}
\hline & \multicolumn{4}{|c|}{ AK5 } & \multicolumn{4}{|c|}{ AK7 } \\
\hline & $\mathrm{Cpx}_{\mathrm{Jd} 23}$ & $\mathrm{Grt}_{\mathrm{Prp} 40}$ & Prg & Opx & $\mathrm{Cpx}_{\mathrm{Jd} 3}$ & $\mathrm{Grt}_{\mathrm{Prp46}}$ & Prg & Opx \\
\hline $\mathrm{Na}_{2} \mathrm{O}$ & 3.28 & 0 & 1.76 & 0 & 0.75 & 0 & 2.51 & 0 \\
\hline $\mathrm{MgO}$ & 12.78 & 10.57 & 15.65 & 28.16 & 16.48 & 12.12 & 16.26 & 29.34 \\
\hline $\mathrm{Al}_{2} \mathrm{O}_{3}$ & 6.41 & 23.10 & 13.09 & 0.88 & 1.01 & 22.03 & 13.25 & 0.93 \\
\hline $\mathrm{SiO}_{2}$ & 54.28 & 39.57 & 45.99 & 54.64 & 54.59 & 40.85 & 45.49 & 56.55 \\
\hline $\mathrm{Cl}$ & 0 & 0 & 0.45 & 0 & 0 & 0 & 0.36 & 0 \\
\hline $\mathrm{K}_{2} \mathrm{O}$ & 0 & 0 & 1.22 & 0 & 0 & 0 & 0.81 & 0 \\
\hline $\mathrm{CaO}$ & 18.88 & 5.34 & 12.78 & 0 & 23.47 & 6.42 & 12.65 & 0 \\
\hline $\mathrm{MnO}$ & 0 & 0.73 & 0 & 0 & 0 & 0.63 & 0 & 0 \\
\hline $\mathrm{TiO}_{2}$ & 0 & 0 & 0.80 & 0 & 0 & 0 & 0.56 & 0 \\
\hline $\mathrm{FeO}$ & 4.38 & 20.69 & 8.25 & 16.33 & 3.79 & 17.95 & 8.12 & 13.19 \\
\hline Сумма & 100.00 & 100.00 & 100.00 & 100.00 & 100.00 & 100.00 & 100.00 & 100.00 \\
\hline
\end{tabular}

Анализы выполнены в ИГ КарНЦ РАН на сканирующем электронном микроскопе Vega Tescan с приставкой для микроанализа Sigma Oxford Instruments INCA. 
изометричные реликтовые зерна магматических орто- и клинопироксена, более крупные, чем удлиненные (метаморфические) зерна этих минералов в основной ткани породы. Эти породы не являются эклогитами, поскольку метаморфический клинопироксен в них представлен не типоморфным для эклогитов омфацитом (содержание жадеитовой молекулы в клинопироксене не превышает 5 \%). Бесплагиоклазовые породы отличаются от разновидностей, содержащих омфацит и плагиоклаз, значительно более высоким содержанием $\mathrm{MgO}(21 \% \mathrm{MgO}$ в бесплагиоклазовых породах по сравнению с 13-16 \% MgO в породах, содержащих плагиоклаз).

Для метагаббро-норитов недеформированных даек района характерны массивные текстуры и апомагматические коронитовые (друзитовые) структуры, хорошая сохранность зерен магматических пироксенов, а нередко и оливина. Недеформированным дайкам метагаббро-норитов не свойственны метаморфические текстуры и выявленная здесь дифференцированность пород по содержанию MgO: более высокая магнезиальность в дайках комплекса лерцолитов-габбро-норитов была отмечена не в центральных частях даек, как в описанном случае, а в зонах закалки [3].

Это обстоятельство свидетельствует в пользу того, что неоднородность химического состава тела вторичная, обусловленная неоднородностью синметаморфических деформаций, обеспечивших миграцию элементов в пределах единого тела. Причина неоднородности деформаций не ясна. По-видимому, макроскопически однородные породы недеформированных даек обладают неоднородностью механических свойств, обуславливающих неоднородность деформаций. Участки тела, испытавшие деформации разного стиля, оказались обогащенными разными элементами. Очевидно, миграции элементов способствовал флюид.

Объяснение сосуществования высокобарического амфибола и «низкобарического» (с малым содержанием жадеитовой молекулы) авгита в бесплагиоклазовом парагенезисе обр. АК7, тоже проблематично. Известно, что условия формирования минеральных метаморфических парагенезисов существенно зависят от состава пород. Чем больше железистость и кремнекислотность базитов, тем при меньших РТ-параметрах в них происходит образование эклогитовых парагенезисов [1, 7, 2]. В обр. АК7 произошел полный распад плагиоклаза - один из основных признаков эклогита, но парагенетичными оказались паргасит и авгит, которому не место в эклогите. По-видимому, при относительно низких содержаниях кремнезема в базитах, их обогащенности магнием и обедненности кальцием и натрием (именно этим характеризуется порода обр. АК7, таблица 1), при высокобарических метаморфических преобразованиях натрий концентруется в паргасите, что и обуславливает авгитовый состав клинопироксена в породе.

Вероятно, детальное изучение рассматриваемого и подобных объектов позволит найти подход к решению означенных проблем.

Исследование выполняется в рамках госзадания ИГ КарНЦ РАН при частичной поддержке РФФИ (Проект 17-05-00329).

\section{Литература}

1. Грин Д.Х., Рингвуд А.Э. Экспериментальное изучение перехода габбро в эклогит и применение результатов этого изучения в петрологии // Петрология верхней мантии. М.: Мир. 1968. С. 9-77.

2. Кориковский С.П. Проградные преобразования габбро-норитов при эклогитизации в температурном интервале $600-700$ ㄷ $\mathrm{C} / /$ Геология и геофизика. 2005. Т. 46. № 12. С. 1352-1366.

3. Степанов В.С. Основной магматизм докембрия Западного Беломорья. Л.: Наука. 1981. 216 с.

4. Травин В.В. Структурная позиция и возраст эклогитизации в районе с. Гридино, Беломорский подвижный пояс // Геотектоника. 2015. № 5. С. 78-93.

5. Шарков Е.В., Красивская И.С., Чистяков А.В. Диспергированный мафит-ультрама-фитовый интрузивный магматизм подвижных зон раннего палеопротерозоя Балтийского щита на примере друзитового (коронитового) комплекса Беломорья // Петрология. 2004. Т. 12. № 10. С. 632-655.

6. Bucher K., Grapes R. Petrogenesis of Metamorphic Rocks. Springer-Verlag Berlin Heidelberg: 2011.428 p.

7. Kullerud K., Flaat K., Davidsen B. High-pressure fluid rock reactions involving Cl-bearing fluids in lower crustal ductile shear zones of Flakstadoy Basic Complex, Lofoten, Norway // J. Petrology. 2001. V. 42 . №7. P. 1349-1372.

8. Travin V.V., Kozlova N.E. Eclogitization of basites in early proterozoic shear zones in the area of the village of Gridino, western Belomorie // Petrology. 2009. V. 17. P. 684-706. 